\title{
Refractory Breast Carcinoma
}

National Cancer Institute

\section{Source}

National Cancer Institute. Refractory Breast Carcinoma. NCI Thesaurus. Code C147965.

Breast carcinoma that does not respond to treatment. 